\title{
Nonlinear dynamic analysis of a turbocharger on foil-air bearings with focus on stability and self-excited vibration
}

Link to publication record in Manchester Research Explorer

\section{Citation for published version (APA):}

Bonello, P., \& Pham, H. (2014). Nonlinear dynamic analysis of a turbocharger on foil-air bearings with focus on stability and self-excited vibration. In Nonlinear dynamic analysis of a turbocharger on foil-air bearings with focus on stability and self-excited vibration

\section{Published in:}

Nonlinear dynamic analysis of a turbocharger on foil-air bearings with focus on stability and self-excited vibration

\section{Citing this paper}

Please note that where the full-text provided on Manchester Research Explorer is the Author Accepted Manuscript or Proof version this may differ from the final Published version. If citing, it is advised that you check and use the publisher's definitive version.

\section{General rights}

Copyright and moral rights for the publications made accessible in the Research Explorer are retained by the authors and/or other copyright owners and it is a condition of accessing publications that users recognise and abide by the legal requirements associated with these rights.

\section{Takedown policy}

If you believe that this document breaches copyright please refer to the University of Manchester's Takedown Procedures [http://man.ac.uk/04Y6Bo] or contact uml.scholarlycommunications@manchester.ac.uk providing relevant details, so we can investigate your claim.

\section{OPEN ACCESS}




\section{NONLINEAR DYNAMIC ANALYSIS OF A TURBOCHARGER ON FOIL-AIR BEARINGS WITH FOCUS ON STABILITY AND SELF-EXCITED VIBRATION}

\author{
Philip Bonello \\ The University of Manchester \\ Manchester, United Kingdom
}

\author{
Hai Pham \\ The University of Manchester \\ Manchester, United Kingdom
}

\begin{abstract}
This paper presents a generic technique for the transient nonlinear dynamic analysis (TNDA) and the static equilibrium stability analysis (SESA) of a turbomachine running on foil air bearings (FABs). This technique is novel in two aspects: (i) the turbomachine structural model is generic, based on uncoupled modes (rotor is flexible, non-symmetric and includes gyroscopic effects; dynamics of support structure can be accommodated); (ii) the finite-difference (FD) state equations of the air films are preserved and solved simultaneously with the state equations of the foil structures and the state equations of the turbomachine modal model, using a readily available implicit integrator (for TNDA) and a predictor-corrector approach (for SESA). An efficient analysis is possible through the extraction of the state Jacobian matrix using symbolic computing. The analysis is applied to the finite-element model of a small commercial automotive turbocharger that currently runs on floating ring bearings (FRBs) and is slightly adapted here for FABs. The results of SESA are shown to be consistent with TNDA. The case study shows that, for certain bearing parameters, it is possible to obtain a wide speed range of stable static equilibrium operation with FABs, in contrast to the present installation with FRBs.
\end{abstract}

\section{INTRODUCTION}

The dynamics of FAB turbomachinery are governed by the interaction between the turbomachine, air films and foil structures. Due to the computational burden involved, the solution process has been subject to simplifications to three aspects of the problem:

- The compressible Reynolds equation (RE) governing the air film pressure distribution;

- The structural model of the turbomachine;

- The foil structure model.

This paper addresses the current simplifications to the first two aspects.
With regards to the first aspect of the problem, as discussed in $[1,2]$, in the case of compressible fluid bearings the RE is a state equation since it includes time as an independent variable [3-8]. The use of Finite Difference (FD)/Finite Element (FE)/Control Volume methods [3-9] to discretize the RE over the air film, creates a grid of $N_{z} \times N_{\theta}$ points representing the pressure field, turning the RE into a set of $N_{z} \times N_{\theta}$ first order ordinary differential equations (ODEs) with time as the independent variable (state equations) [1,2]. Additionally, the air film gap at a given location is a function of the foil deformation there, apart from the journal displacement. Hence, a further $n_{\text {foil }}$ state equations are introduced and the total number of state equations to be solved would be equal to $2 H+n_{b}\left(N_{z} \times N_{\theta}+n_{\text {foil }}\right)$ where $H$ is the number of rotor modes and casing modes (if considered), and $n_{b}$ is the number of bearings $[1,2]$. Such a large nonlinear system would be numerically "stiff", requiring very small time-steps to maintain a given accuracy if an explicit numerical integration scheme is used [10]. An implicit integrator uses a larger step size for a given accuracy [10]. However, this advantage would be useless without an efficient means of calculating the required Jacobian matrix of such a large system at each time step [10]. Hence, for a realistic rotor system, the simultaneous solution of the complete system of state equations has hitherto been avoided. In an attempt to make the integration faster, it has been common practice to adopt a non-simultaneous solution approach wherein the air-film ODEs are uncoupled from the rest and treated as algebraic rather than state equations, as in [38]. In such works, the air-film ODEs were approximated into a system of algebraic equations by replacing the term $\frac{\partial p}{\partial t}$ by a backward difference approximation and approximating the current values of air film gap $h$ and $\frac{\partial h}{\partial t}$ using the journal and foil state variables at the previous time step $t_{k-1}$. These resulting equations were then solved iteratively to yield the 
pressure distribution and, hence, the bearing forces at $t_{k}$. These latter were then used in the integration of the rotor ODEs to yield the journal displacements and velocities at $t_{k}$. The approximate pressure distribution at $t_{k}$ was also used to update the foil deflection distribution.

Since the above-described methods do not reflect the true simultaneously coupled nature of the state variables of the original stiff system, they are inevitably slow through the need to maintain sufficiently small time steps [1,2]. In fact, such approximations required checking either by repeated calculations for different time steps [6] or as part of an iterative feed-back loop to restore the coupling between the subsystems [8]. In previous research [1, 2], the authors developed two alternative techniques (respectively based on FD and Galerkin Reduction) to preserve the state equations of the air films and solve them simultaneously with the other state equations. In the present paper, the state equations are similarly preserved but only FD is used and symbolic computing is used as an alternative to the vectorised formulation adopted in [1, 2] for the efficient computation of the Jacobian.

With regard to the second simplification aspect listed at the start, it is noted that most (if not all) research that considered nonlinear FABs has assumed a rigid rotor. For example, the above-mentioned works [1-8] assumed a simple symmetric rigid rotor-bearing system. Other works considered rigid rotors with four degrees of freedom (DOFs) (corresponding to translation and rotation in each of the $x y, y z$ planes) [11] or five DOFs (where an additional axial DOF was considered to account for an air foil thrust bearing) [12].

The turbocharger considered in this paper is typically run at $150,000 \mathrm{rpm}(2.5 \mathrm{kHz})$. Hence, the assumption of rotor rigidity is not appropriate. Moreover, at such high speeds, the support structure dynamics may be influential. The modal technique presented in this paper can accommodate both rotor and support structure flexibility, in a similar fashion to the approach developed by one of the authors for turbochargers on oil bearings (FRBs) [13].

\section{NOMENCLATURE}

$c^{(n)}$
$c_{0}$
$\mathbf{f}_{n}$
$\tilde{h}^{(n)}$
$H$
$\mathbf{H}_{\mathbf{f}_{n}}, \mathbf{H}_{\mathbf{J}_{n}}, \ldots$
$k_{\mathrm{b}}^{(n)}, \tilde{k}_{\mathrm{b}}^{(n)}$
$k_{\mathrm{b} 0}$
$L^{(n)}$
$n$
$n_{\text {state }}$
$N_{z}, N_{\theta}$

\begin{tabular}{|c|c|}
\hline $\begin{array}{l}p^{(n)}(\zeta, \theta) \\
p_{a}, \tilde{p}^{(n)}\end{array}$ & $\begin{array}{l}\text { absolute air pressure at }(\zeta, \theta) \text { for FAB } n \\
\text { atmospheric pressure, } p^{(n)} / p_{a} \text { resp. }\end{array}$ \\
\hline$\tilde{p}_{\mathrm{g}, \theta}^{(n)}$ & average gauge pressure at $\theta$, eq. (8) \\
\hline$\widetilde{\mathbf{p}}_{\mathrm{g}, \theta}^{(n)}$ & vector of values of $\tilde{p}_{\mathrm{g}, \theta}^{(n)}$ at discrete $\theta$ values \\
\hline $\mathbf{P}$ & diagonal matrix defined by eq. (4) \\
\hline $\mathbf{q}$ & vector of modal coordinates, eq. (1) \\
\hline$R^{(n)}$ & undeformed radius of $\mathrm{FAB} n$ \\
\hline $\mathbf{S}$ & vector of state variables, eqs. (16), (17) \\
\hline $\mathbf{S}_{\mathbf{E}}$ & static equilibrium solution of eq. (16) \\
\hline $\mathbf{u}, \mathbf{w}$ & vectors of unbalance and gravity forces resp. \\
\hline$\widetilde{W}^{(n)}$ & radial foil deflection (at $\theta$ ) divided by $c^{(n)}$ \\
\hline$\widetilde{\mathbf{w}}^{(n)}$ & vector of values of $\widetilde{w}^{(n)}$ at discrete $\theta$ values \\
\hline$x_{\text {rel }}^{(n)}, y_{\text {rel }}^{(n)}$ & relative displacements at FAB $n$ (Figure 1(b)) \\
\hline$z^{(n)}$ & axial displacement from bearing mid-section \\
\hline$\zeta$ & $=Z^{(n)} / R^{(n)}$ \\
\hline$\theta$ & angular local bearing coordinate (Figure $1(\mathrm{~b})$ ) \\
\hline$\Lambda^{(n)}$ & bearing number, defined under eq. (5) \\
\hline$\lambda_{\mathrm{L}}$ & linearization eigenvalue with highest real part \\
\hline$\mu$ & viscosity \\
\hline$\eta$ & damping loss factor of foil structure \\
\hline$\varepsilon_{x, y}^{(n)}$ & $x_{\mathrm{rel}}^{(n)} / c^{(n)}, y_{\mathrm{rel}}^{(n)} / c^{(n)}$ \\
\hline $\boldsymbol{\varepsilon}^{(n)}$ & vector of $\varepsilon_{x, y}^{(n)}$, eq. (12) \\
\hline$\psi^{(n)}$ & $=\tilde{p}^{(n)} \tilde{h}^{(n)}$ \\
\hline $\boldsymbol{\Psi}^{(n)}$ & vector of values of $\psi^{(n)}$ at discrete $\zeta, \theta$ valu \\
\hline $\boldsymbol{\varphi}_{\mathbf{f}_{n}}^{(r)}, \boldsymbol{\varphi}_{\mathbf{J}_{n}}^{(r)}, \ldots$ & $\begin{array}{l}\text { eigenmodes of mode } r=1 \ldots H \text { at selected } \\
\text { degrees of freedom (see below eq. (3)) }\end{array}$ \\
\hline$\Lambda$ & $\begin{array}{l}\text { diagonal matrix of squares of natural } \\
\text { frequencies, eq. (1) }\end{array}$ \\
\hline $\boldsymbol{\rho}^{(n)}$ & right-hand of FD transformed equation (5) \\
\hline $\boldsymbol{\sigma}^{(n)}$ & vector function defined by eq. (14) \\
\hline$\chi$ & nonlinear vector function of $\mathbf{s}$, eq. (16) \\
\hline$\tau$ & non-dimensional time $(=\Omega t / 2)$ \\
\hline$\Omega$ & rotational speed $(\mathrm{rad} / \mathrm{s})$ \\
\hline$\omega$ & general frequency $(\mathrm{rad} / \mathrm{s})$ \\
\hline
\end{tabular}

\section{COMPUTATIONAL ANALYSIS}

\subsection{State Equations}

Figure 1(a) shows a generic turbocharger assembly fitted with two FABs. Figure 1(b) shows the cross-section of FAB $n$ $(n=1,2)$ where $\mathrm{J}_{n}, \mathrm{~B}_{n}$ respectively denote the centres of the journal and bearing housing. The "linear part" of the assembly is defined as the system that remains in Figure 1(a) when the FABs are replaced by gaps i.e. the linear part comprises the uncoupled (free-free) rotor and the support structure. Let $\mathbf{q}$ be the $H \times 1$ column matrix (vector) of modal coordinates of the linear part and $\boldsymbol{\Lambda}$ the diagonal matrix of the squares of the natural frequencies. The equations of motion are written as:

$$
\ddot{\mathbf{q}}+\Lambda \mathbf{q}=\mathbf{H}_{\mathbf{u}}^{\mathrm{T}} \mathbf{u}+\mathbf{H}_{\mathbf{w}}^{\mathrm{T}} \mathbf{w}+\mathbf{H}_{\mathbf{g}}^{\mathrm{T}} \mathbf{P} \mathbf{H}_{\boldsymbol{\alpha}} \dot{\mathbf{q}}+\sum_{n=1}^{2} \mathbf{H}_{\mathbf{f}_{n}}^{\mathrm{T}} \mathbf{f}_{n}
$$


where:

$$
\mathbf{f}_{n}=\left[\begin{array}{ll}
F_{x}^{(n)} & F_{y}^{(n)}
\end{array}\right]^{\mathrm{T}}
$$

is the vector of $x, y$ forces exerted by FAB $n$ on its journal $\mathrm{J}_{n}$.

$$
\mathbf{H}_{\mathbf{f}_{n}}=\mathbf{H}_{\mathbf{J}_{n}}-\mathbf{H}_{\mathbf{B}_{n}}=\left[\begin{array}{lll}
\boldsymbol{\varphi}_{\mathbf{J}_{n}}^{(1)} & \cdots & \boldsymbol{\varphi}_{\mathbf{J}_{n}}^{(H)}
\end{array}\right]-\left[\begin{array}{lll}
\boldsymbol{\varphi}_{\mathbf{B}_{n}}^{(1)} & \cdots & \boldsymbol{\varphi}_{\mathbf{B}_{n}}^{(H)}
\end{array}\right]
$$

$\boldsymbol{\varphi}_{\mathrm{J}_{n}}^{(r)}, r=1 \ldots H$, is the mass-normalised $2 \times 1$ eigenvector whose rows respectively define the $x$ and $y$ displacements of $\mathbf{J}_{n}$ in mode no. $r$. Similarly for $\boldsymbol{\varphi}_{\mathbf{B}_{n}}^{(r)} \cdot \mathbf{H}_{\mathbf{u}}$ and $\mathbf{H}_{\mathbf{w}}$ are the matrices whose columns are the mass-normalised eigenvectors $\boldsymbol{\varphi}_{\mathbf{u}}^{(r)}$, $\boldsymbol{\varphi}_{\mathrm{w}}^{(r)}$ evaluated at the degrees of freedom corresponding to the directions and locations of the elements of the vector of unbalance forces $\mathbf{u}$ and the vector of static loads $\mathbf{w}$. Since the rotor is statically determinate, its distributed weight could be replaced by two equivalent concentrated loads at the bearing journals.

The modes in eq. (1) pertain to the linear part at zero rotor speed. The right-hand term $\mathbf{H}_{\mathbf{g}}^{\mathrm{T}} \mathbf{P} \mathbf{H}_{\boldsymbol{\alpha}} \dot{\mathbf{q}}$ accounts for the gyroscopic effect on the rotating nonlinear assembly. This effect is assumed to be concentrated at $G$ points on the rotor. $\mathbf{P}$ is the diagonal matrix:

$$
\mathbf{P}=\Omega \operatorname{diag}\left\{\left[\begin{array}{lllll}
-I_{1} & I_{1} & \cdots & -I_{G} & I_{G}
\end{array}\right]\right\}
$$

where: $\Omega$ is the rotational speed $(\mathrm{rad} / \mathrm{s}), I_{k}$ is the polar moment of inertia at rotor location $k(=1 \ldots G) . \quad \mathbf{H}_{\mathbf{g}}$ and $\mathbf{H}_{\boldsymbol{\alpha}}$ are the matrices whose columns are the mass-normalised eigenvectors $\varphi_{\mathrm{g}}^{(r)}, \boldsymbol{\varphi}_{\alpha}^{(r)}$ taken at the degrees of freedom corresponding to the directions and locations of the elements of the gyroscopic moment and rotation vectors $\mathbf{g}$ and $\boldsymbol{\alpha}$ defined in reference [13] (the latter vector is given the symbol $\boldsymbol{\theta}$ in [13]).

For FAB $n$ of radius $R^{(n)}$ and length $L^{(n)}$ (Figure 1(b)), let $p^{(n)}(\zeta, \theta)$ denote the distribution of the air film pressure (absolute) where $\zeta=\frac{z^{(n)}}{R^{(n)}}$. This distribution is then governed by the isothermal RE:

$\frac{\partial \psi^{(n)}}{\partial \tau}=$

$\frac{1}{\Lambda^{(n)}}\left\{\frac{\partial}{\partial \theta}\left[\psi^{(n)}\left(\tilde{h}^{(n)} \frac{\partial \psi^{(n)}}{\partial \theta}-\psi^{(n)} \frac{\partial \tilde{h}^{(n)}}{\partial \theta}\right)\right]+\frac{\partial}{\partial \zeta}\left[\psi^{(n)}\left(\tilde{h}^{(n)} \frac{\partial \psi^{(n)}}{\partial \zeta}-\right.\right.\right.$ $\left.\left.\left.\psi^{(n)} \frac{\partial \widetilde{h}^{(n)}}{\partial \zeta}\right)\right]\right\}-\frac{\partial \psi^{(n)}}{\partial \theta}$

where: $\tau=\Omega t / 2$ is non-dimensional time, the bearing number $\Lambda^{(n)}=\frac{6 \mu \Omega}{p_{\mathrm{a}}}\left(\frac{R^{(n)}}{c^{(n)}}\right)^{2}, \mu$ is the air viscosity, $c^{(n)}$ is the radial clearance with no foil deflection, $\psi^{(n)}=\tilde{p}^{(n)} \tilde{h}^{(n)}, \tilde{p}^{(n)}=\frac{p^{(n)}}{p_{\mathrm{a}}}$, $p_{\mathrm{a}}$ being the atmospheric pressure and $\tilde{h}^{(n)}$ the nondimensional air-film gap at a position $(\zeta, \theta)$ :

$$
\tilde{h}^{(n)}=1-\varepsilon_{x}^{(n)} \cos \theta-\varepsilon_{y}^{(n)} \sin \theta+\widetilde{w}^{(n)}
$$

In equation (6): $\varepsilon_{x, y}^{(n)}=x_{\text {rel }}^{(n)} / c^{(n)}, y_{\text {rel }}^{(n)} / c^{(n)}$ are the nondimensional Cartesian displacements of $\mathrm{J}_{n}$ relative to $\mathrm{B}_{n}$ (Figure $1(\mathrm{~b}))\left(\mathrm{B}_{n}\right.$ may be dynamic); $\widetilde{W}^{(n)}=\frac{w^{(n)}}{c^{(n)}}$ is the nondimensional foil deflection at a position $(\zeta, \theta)$.

The foil structure used in this paper assumes that the variation of the deflection of the foil in the axial direction is negligible [14]:

$$
\frac{d \widetilde{W}^{(n)}}{d \tau}=\frac{2}{\eta}\left(\frac{\tilde{p}_{\mathrm{g}, \theta}^{(n)}}{\tilde{\hat{k}}_{\mathrm{b}}^{(n)}}-\widetilde{W}^{(n)}\right)
$$

where: $\widetilde{w}^{(n)}=\widetilde{w}^{(n)}(\theta), \tilde{k}_{\mathrm{b}}^{(n)}=k_{\mathrm{b}}^{(n)} c^{(n)} / p_{\mathrm{a}} \quad$ is the nondimensional form of $k_{\mathrm{b}}^{(n)}$, the stiffness per unit area of the foil structure $\left(\mathrm{N} / \mathrm{m}^{3}\right)$ and $\tilde{p}_{\mathrm{g}, \theta}^{(n)}$ is the average of the non-dimensional gauge pressure $\tilde{p}_{\mathrm{g}}^{(n)}\left(=\tilde{p}^{(n)}(\zeta, \theta)-1\right.$ ) over the $\zeta$ (or $z^{(n)}$ )direction for a given $\theta$ :

$$
\tilde{p}_{\mathrm{g}, \theta}^{(n)}=\frac{R^{(n)}}{L^{(n)}} \int_{-L^{(n)} / 2 R^{(n)}}^{L^{(n)} / 2 R^{(n)}}\left\{\frac{\psi^{(n)}}{\widetilde{n}^{(n)}}-1\right\} d \zeta
$$

As in $[6,7]$, the damping in the foil structure is quantified by a hysteretic loss factor $\eta$. However, $\eta$ is only defined for harmonic vibration [15] and its equivalent viscous damping coefficient in the time domain is $k_{\mathrm{b}}^{(n)} \eta / \omega, \omega \mathrm{rad} / \mathrm{s}$ being the frequency of the vibration. Hence, with this damping model, time domain analysis for arbitrary response inevitably necessitates the use of an assumed equivalent viscous damping coefficient. In [6, 7] alternative equivalent coefficients of $k_{\mathrm{b}}^{(n)} \eta / \Omega$ and $k_{\mathrm{b}}^{(n)} \eta / \omega$ were used (the $\omega$ in the latter was prescribed). In the present work, the former option $\left(k_{\mathrm{b}}^{(n)} \eta / \Omega\right)$ is used throughout (as per equation (7)). The validity of this assumption for (self-excited) limit cycles (which have a fundamental frequency unrelated to the rotational speed, and harmonics) was tested in [2] using a frequency domain solution process (Harmonic Balance) which can accommodate the correct damping expression for each unknown frequency component. The cases studied in [2] showed that the assumption of $k_{\mathrm{b}}^{(n)} \eta / \Omega$ in the time domain integration process had little effect on the limit cycle that the trajectory approaches in the steady-state.

The rotor equations (1) are linked to the bearing equations (5), (7) through the forces $\mathbf{f}_{n}$, which are obtained by integrating the air film pressure distribution in FAB $n$ :

$$
\mathbf{f}_{n}=-p_{\mathrm{a}}\left(R^{(n)}\right)^{2} \int_{\zeta=-L^{(n)} / 2 R^{(n)}}^{L^{(n)} / 2 R^{(n)}} \int_{\theta=0}^{2 \pi}\left(\frac{\psi^{(n)}}{\widetilde{h}^{(n)}}-1\right)\left[\begin{array}{c}
\cos \theta \\
\sin \theta
\end{array}\right] d \theta d \zeta
$$




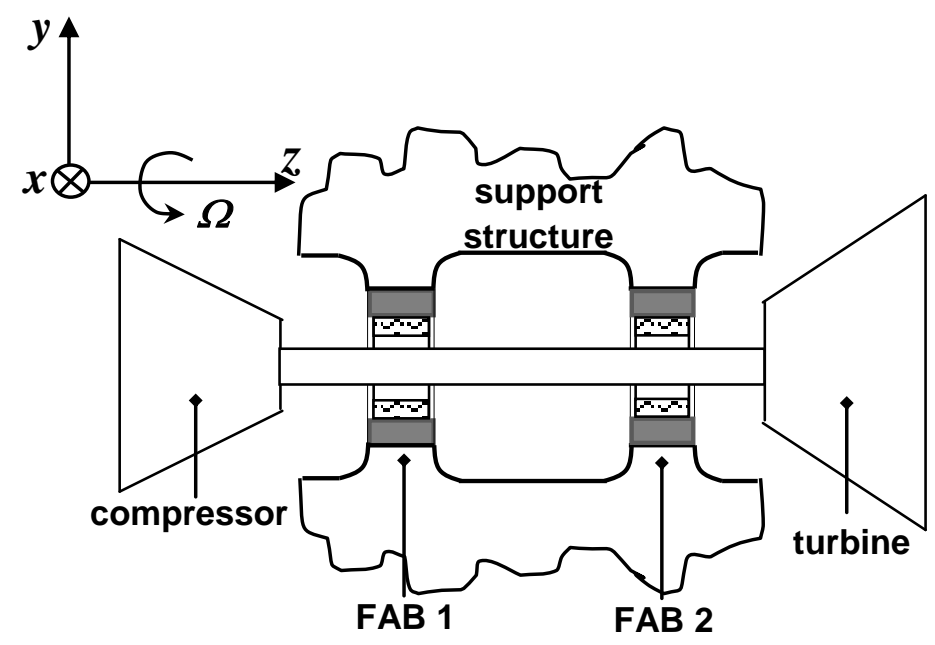

(a)

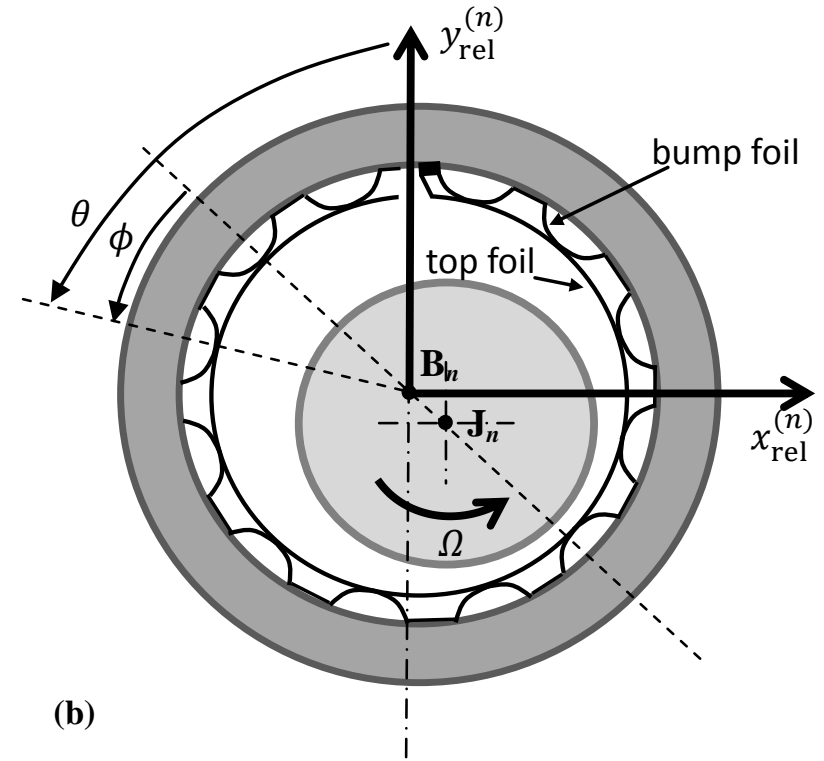

(b)

Figure 1. Turbocharger assembly with FABs: (a) turbocharger schematic; (b) cross-section of FAB

The system response is obtained by solving simultaneously the three sets of equations (1), (5), (7). This can be done using readily available time domain implicit integration routines after the transformation of equations sets (5), (7) into FD format.

Since each bearing is open to atmosphere at both ends, symmetry can be exploited and the FD grid need only cover half the axial length of the bearing. The rectangular grid has $N_{z} \times N_{\theta}$ points where $\zeta=\zeta_{i}, \quad i=1, \ldots, N_{z}, \quad \theta=\theta_{j}, \quad j=$ $1, \ldots, N_{\theta}$. It is noted that the bearing edge, where $\psi^{(n)}=\tilde{h}^{(n)}$, is excluded from the grid. However, this boundary condition is considered when estimating partial derivatives and integrating. Let:

$$
\begin{aligned}
& \boldsymbol{\Psi}^{(n)}=\left[\begin{array}{lll}
\cdots & \psi_{i, j}^{(n)} & \cdots
\end{array}\right]^{\mathrm{T}}\left(N_{z} N_{\theta} \times 1\right) \\
& \widetilde{\mathbf{w}}^{(n)}=\left[\begin{array}{lll}
\cdots & \widetilde{w}_{j}^{(n)} & \cdots
\end{array}\right]^{\mathrm{T}}\left(N_{\theta} \times 1\right) \\
& \boldsymbol{\varepsilon}^{(n)}=\left[\begin{array}{ll}
\varepsilon_{x}^{(n)} & \varepsilon_{y}^{(n)}
\end{array}\right]^{\mathrm{T}}
\end{aligned}
$$

where $\psi_{i, j}^{(n)}=\psi^{(n)}\left(\zeta_{i}, \theta_{j}\right), \widetilde{w}_{j}^{(n)}=\widetilde{w}^{(n)}\left(\theta_{j}\right)$ and

$$
\boldsymbol{\varepsilon}^{(n)}=\boldsymbol{\varepsilon}^{(n)}(\mathbf{q})=\mathbf{H}_{\mathbf{f}_{n}} \mathbf{q} / c^{(n)}
$$

Using central-difference formulae $[16,17]$ to approximate the partial derivatives in eq. (5), this equation can be transformed into a set of state equations whose right hand side is denoted by a vector $\boldsymbol{\rho}^{(n)}$. Let $\widetilde{\mathbf{p}}_{\mathrm{g}, \theta}^{(n)}$ denote the vector of pressures $\tilde{p}_{\mathrm{g}, \theta}^{(n)}\left(\theta_{j}\right)$ computed from the discrete form of equation (8) and let the discretised right hand side of equation (7) be denoted as:

$$
\boldsymbol{\sigma}^{(n)} \equiv \frac{2}{\eta}\left\{\frac{\widetilde{\mathbf{p}}_{\mathrm{g}, \theta}^{(n)}}{\tilde{k}_{\mathbf{b}}^{(n)}}-\widetilde{\mathbf{w}}^{(n)}\right\}
$$

Both $\boldsymbol{\rho}^{(n)}$ and $\boldsymbol{\sigma}^{(n)}$ are nonlinear functions of $\boldsymbol{\Psi}^{(n)}, \widetilde{\mathbf{w}}^{(n)}, \boldsymbol{\varepsilon}^{(n)}(\mathbf{q})$. Hence, the state equations of the complete assembly can be written as:

$$
\begin{aligned}
& \boldsymbol{\psi}^{(1) \prime}=\boldsymbol{\rho}^{(1)}\left(\boldsymbol{\Psi}^{(1)}, \widetilde{\mathbf{w}}^{(1)}, \boldsymbol{\varepsilon}^{(1)}(\mathbf{q})\right) \\
& \widetilde{\mathbf{w}}^{(1) \prime}=\boldsymbol{\sigma}^{(1)}\left(\boldsymbol{\Psi}^{(1)}, \widetilde{\mathbf{w}}^{(1)}, \boldsymbol{\varepsilon}^{(1)}(\mathbf{q})\right) \\
& \boldsymbol{\psi}^{(2) \prime}=\boldsymbol{\rho}^{(2)}\left(\boldsymbol{\psi}^{(2)}, \widetilde{\mathbf{w}}^{(2)}, \boldsymbol{\varepsilon}^{(2)}(\mathbf{q})\right) \\
& \widetilde{\mathbf{w}}^{(2) \prime}=\boldsymbol{\sigma}^{(2)}\left(\boldsymbol{\psi}^{(2)}, \widetilde{\mathbf{w}}^{(2)}, \boldsymbol{\varepsilon}^{(2)}(\mathbf{q})\right)
\end{aligned}
$$

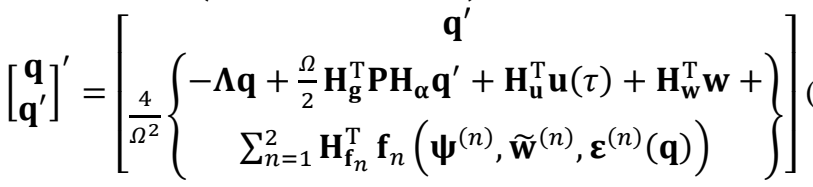

\subsection{Transient Nonlinear Dynamic Analysis (TNDA)}

The system in equation (15) is in the general form required by Matlab integrator routines [10]:

$$
\mathbf{s}^{\prime}=\chi(\tau, \mathbf{s})
$$

where the state vector $\mathbf{s}$

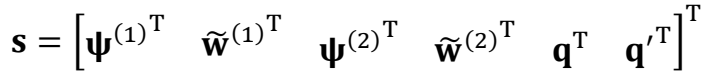

is $n_{\text {state }}=2\left(N_{z} N_{\theta}+N_{\theta}\right)+2 H$ elements long. In view of the numerical stiffness of the systems, the implicit integrator function ode23s was used [10]. This is based on the ModifiedRosenbrock algorithm and has adaptive time-step control to maintain the numerical error with a prescribed tolerance. As 
discussed in the Introduction, it is only possible to take advantage of this function (and other stiff solvers in the Matlab ode suite), if a user-written function for the rapid computation of the Jacobian matrix $\frac{\partial \chi}{\partial s}$ at each time-step can be provided. An analysis of the Jacobian expression reveals that the computational burden lies in the calculation of the following submatrices:

$$
\begin{aligned}
& \boldsymbol{\partial}\left[\boldsymbol{\rho}^{(n)^{\mathrm{T}}} \quad \boldsymbol{\sigma}^{(n)^{\mathrm{T}}}\right]^{\mathrm{T}} / \boldsymbol{\partial}\left[\boldsymbol{\Psi}^{(n)^{\mathrm{T}}} \quad \widetilde{\boldsymbol{w}}^{(n)^{\mathrm{T}}}\right]^{\mathrm{T}},
\end{aligned}
$$

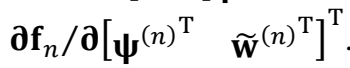

Expressions for the above matrices could be obtained using one of two alternative methods: (i) using Matlab-style vectorized formulation that minimises matrix multiplication, as done in [2]; (ii) using symbolic computing. The latter approach was used for this research. Code was developed to generate symbolic expressions for the elements in the above matrices in terms of the elements in $\boldsymbol{\Psi}^{(n)}, \widetilde{\mathbf{w}}^{(n)}, \boldsymbol{\varepsilon}^{(n)}$ (using Matlab Symbolic Toolbox $^{\mathrm{TM}}$ ) and then to write these expressions into a subroutine.

\subsection{Static Equilibrium Stability Analysis (SESA)}

With reference to eq. (16), the static equilibrium condition at a given rotational speed can be obtained directly by finding the solution $\mathbf{s}=\mathbf{s}_{\mathbf{E}}$ of the system of nonlinear algebraic equations $\left.\boldsymbol{\chi}(t, \mathbf{s})\right|_{\mathbf{u}=\mathbf{0}}=\mathbf{0}$, whose left hand side is a nonlinear vector function of $\mathbf{s}$ only (since $\mathbf{u}$ is omitted). The stability of small perturbations $\Delta \mathbf{S}$ about $\mathbf{S}=\mathbf{s}_{\mathbf{E}}$ is governed by the linear relation $(\Delta \mathbf{s})^{\prime}=\left.\frac{\partial \chi}{\partial \mathbf{s}}\right|_{\mathbf{u}=\mathbf{0}, \mathbf{s}=\mathbf{s}_{\mathbf{E}}} \Delta \mathbf{s}$. The solution of this linearized system is given by $\Delta \mathbf{s}=\sum_{k=1}^{n_{\text {state }}} C_{k} \mathbf{v}_{k} \mathrm{e}^{\lambda_{k} \tau}$ where $\lambda_{k}, k=1 \ldots n_{\text {state }}$, are the eigenvalues of the Jacobian matrix $\left.\frac{\partial \chi}{\partial s}\right|_{\mathbf{u}=0, \mathbf{s}=\mathbf{s}_{\mathbf{E}}}$, and $\mathbf{v}_{k}$, $C_{k}$ are eigenvectors and arbitrary constants respectively. Hence, the stability of the static equilibrium $\mathbf{s}=\mathbf{s}_{\mathbf{E}}$ can be investigated by examining the leading eigenvalue $\lambda_{\mathrm{L}}$ (i.e. the one whose real part is nearest to $+\infty): \operatorname{Re}\left\{\lambda_{\mathrm{L}}\right\}$ is the growth factor of the dominant component of the perturbation and $\operatorname{Im}\left\{\left|\lambda_{\mathrm{L}} / 2\right|\right\}$ is the ratio of its frequency to the rotational speed. The system $\left.\boldsymbol{\chi}(t, \mathbf{s})\right|_{\mathbf{u}=\mathbf{0}}=\mathbf{0}$ was solved over a range of speeds using a predictor-corrector continuation scheme [18]. In this process the initial approximation ('predictor') to $\mathbf{s}_{\mathbf{E}}$ at the current speed was obtained from the solution at the previous speed and the damped Newton-Raphson Method ('corrector') was used to converge it to $\mathbf{S}_{\mathbf{E}}$. The predictor at the first speed in the range was taken from the steady-state TNDA solution. The Jacobian expression of the previous section was used both by the corrector and the subsequent eigenvalue analysis (apart from TNDA).

\section{SIMULATIONS AND DISCUSSION}

The analysis was applied to a small commercial automotive turbocharger rotor whose finite element (FE) model was supplied by industry (Figure 2(a)). This model was somewhat similar to that used in the FRB analysis in [19]: the turbine (shaded) was integral with the shaft (i.e. one material code used), with discs added to correct the diametral and polar moments of inertia; the aluminium compressor was modeled as discs added to the steel shaft, correcting both the mass and the moments of inertia. It is also noted that the simple twodisc/flexible shaft rotor model used in the FRB analysis in [13] is approximately dynamically equivalent to the present one. Since the supplied rotor model was used on FRBs, the shaft diameter at each of the bearing locations was increased from $11 \mathrm{~mm}$ to $20 \mathrm{~mm}$ over a $20 \mathrm{~mm}$ length of shaft in order to accommodate the realistically-sized FABs used in the present analysis, as indicated in Figure 2(a). Figure 2(b) shows the first four free-free undamped modes of the modified rotor in one plane at zero rotational speed. These comprise: two rigid body modes $(0 \mathrm{~Hz})$ respectively describing translation and rotation about the mass centre; two flexural modes $(1.2 \mathrm{kHz}, 3.0 \mathrm{kHz})$. The next highest flexural mode occurred at $6.1 \mathrm{kHz}$ and hence was considered not to be influential within the operating speed range of the present analysis $(0-3000 \mathrm{rev} / \mathrm{s})$, which focuses on self-excited vibration, in which sub-synchronous frequency components dominate. Also, the support structure was taken to be rigid. Hence, in the above nonlinear analysis, $H=8$ (i.e. 4 free-free rotor modes for each of the $x z, y z$ planes) and $\boldsymbol{\varphi}_{\mathbf{B}_{n}}^{(1, \ldots, 8)}=\mathbf{0}$. It is noted that, if the support structure modal properties were known and influential, then this would be simply accommodated by adding further columns to $\mathbf{H}_{\mathbf{f}_{n}}$ (eq. (3)) for which $\boldsymbol{\varphi}_{\mathbf{J}_{n}}^{(9, \ldots)}=\mathbf{0}$ and $\boldsymbol{\varphi}_{\mathbf{B}_{n}}^{(9, \ldots)} \neq \mathbf{0}$. The gyroscopic effect was discretised at the locations shown in Figure 2(b).

Table 1. FAB length, radial clearance and foil stiffness for different simulation tests (the radii of both bearings are $10 \mathrm{~mm}$ for all tests; $c_{0}=32 \times 10^{-6} \mathrm{~m} ; k_{\mathrm{b} 0}=4.739 \mathrm{GN} / \mathrm{m}^{3}$ )

\begin{tabular}{|c|c|c|c|}
\hline $\begin{array}{c}\text { test } \\
\text { no. }\end{array}$ & $\begin{array}{c}L^{(n)} / R^{(n)} \\
\text { FAB1, FAB2 }\end{array}$ & $\begin{array}{c}c^{(n)} \\
\text { FAB1, FAB2 }\end{array}$ & $\begin{array}{c}k_{\mathrm{b}}^{(n)} \\
\text { FAB1, FAB2 }\end{array}$ \\
\hline 1 & 1,1 & $0.25 c_{0}, 0.25 c_{0}$ & $5 k_{\mathrm{b} 0}, 5 k_{\mathrm{b} 0}$ \\
\hline 2 & 1,2 & $0.25 c_{0}, 0.25 c_{0}$ & $5 k_{\mathrm{b} 0}, 5 k_{\mathrm{b} 0}$ \\
\hline 3 & 2,2 & $0.25 c_{0}, 0.25 c_{0}$ & $5 k_{\mathrm{b} 0}, 5 k_{\mathrm{b} 0}$ \\
\hline 4 & 2,2 & $0.25 c_{0}, 0.25 c_{0}$ & $k_{\mathrm{b} 0}, k_{\mathrm{b} 0}$ \\
\hline 5 & 2,2 & $0.25 c_{0}, 0.25 c_{0}$ & $0.5 k_{\mathrm{b} 0}, 0.5 k_{\mathrm{b} 0}$ \\
\hline 6 & 2,2 & $0.1 c_{0}, 0.1 c_{0}$ & $5 k_{\mathrm{b} 0}, 5 k_{\mathrm{b} 0}$ \\
\hline 7 & 2,2 & $0.1 c_{0}, 0.1 c_{0}$ & $k_{\mathrm{b} 0}, k_{\mathrm{b} 0}$ \\
\hline 8 & 2,2 & $0.1 c_{0}, 0.1 c_{0}$ & $0.5 k_{\mathrm{b} 0}, 0.5 k_{\mathrm{b} 0}$ \\
\hline
\end{tabular}

The radii $R^{(1)}, R^{(2)}$ of the FABs used in the analysis were both $10 \mathrm{~mm}$. The other FAB parameters were adjusted as shown in Table 1 with reference to $R^{(n)}, c_{0}$ and $k_{\mathrm{b} 0}$ where $c_{0}=32 \times$ $10^{-6} \mathrm{~m}$ and $k_{\mathrm{b} 0}=4.739 \mathrm{GN} / \mathrm{m}^{3}$ are, respectively, the radial clearance and foil stiffness of the larger standard FAB used in $[6,7]$ (which had a radius of $19.05 \mathrm{~mm}$ and length of $38.1 \mathrm{~mm}$ ). In all simulations, $p_{a}=101325 \mathrm{~Pa}, \mu=1.95 \times 10^{-5} \mathrm{Ns} / \mathrm{m}^{2}$ and foil structure loss factor $\eta=0.25[6,7]$. The analysis in this paper focuses on self-excited instabilities and so, no rotor unbalance was considered in the case study. 
The FD grid used for each FAB was $N_{z}=7, N_{\theta}=72$ (i.e. the full extent of each FAB was covered by a $15 \times 73$ grid). This means that the number of state equations (15) was 1168. All simulations were implemented in Matlab on a standard laptop computer with Intel® $\mathrm{Core}^{\mathrm{TM}} i 7$ Processor.

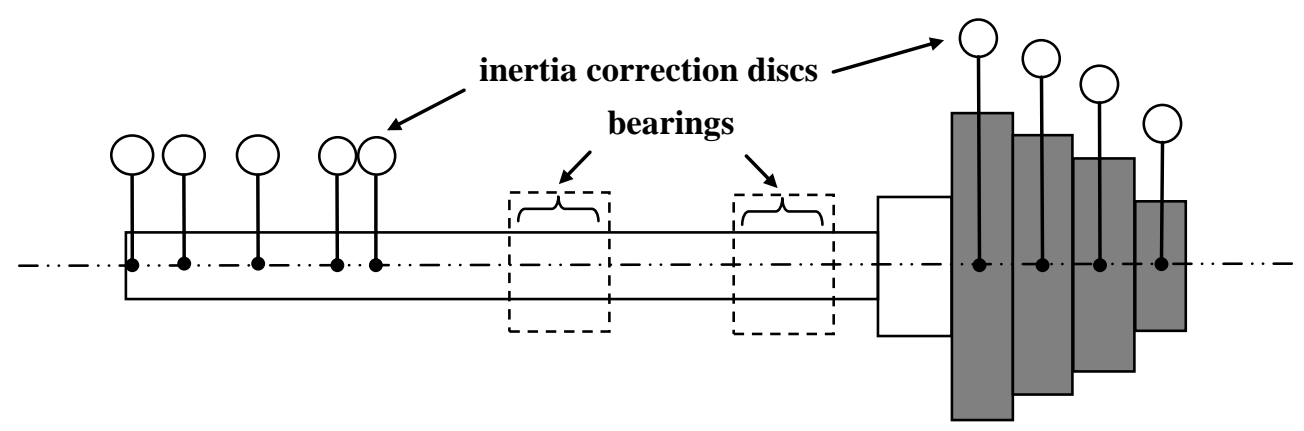

(a)

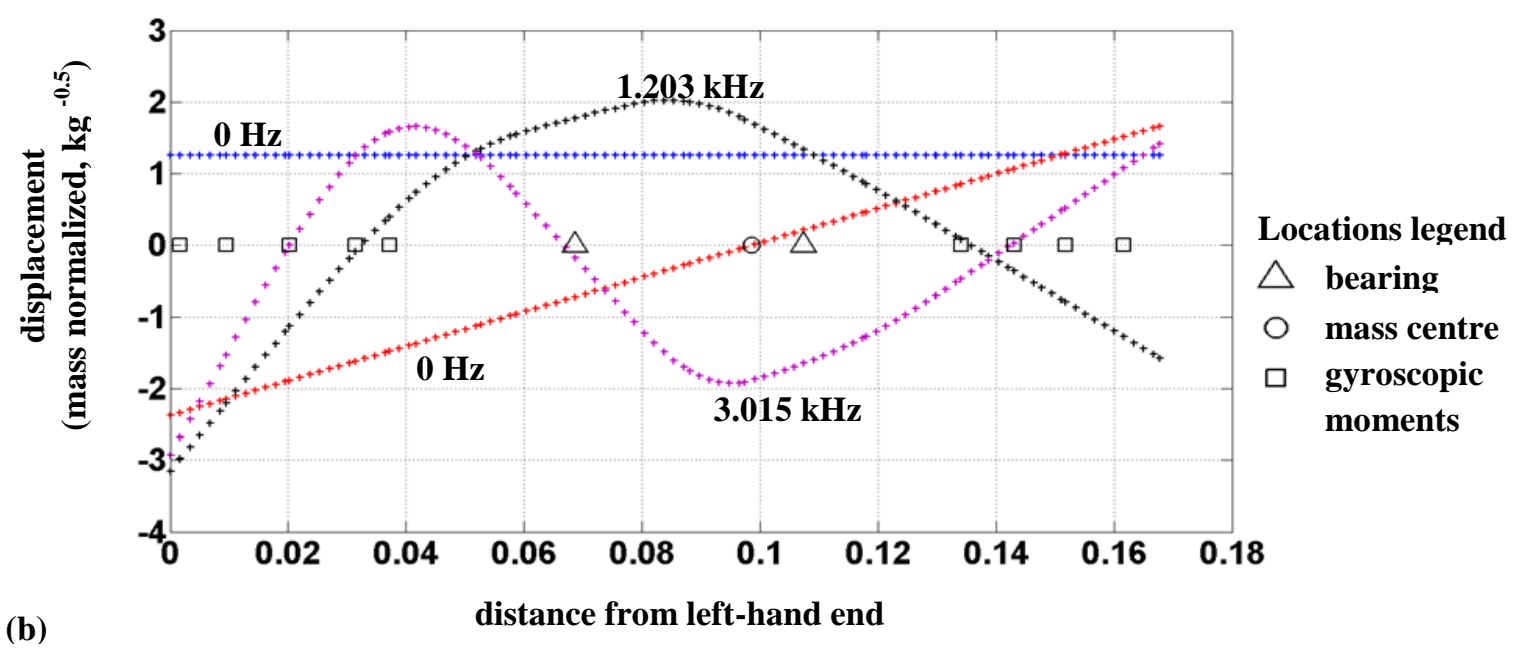

Figure 2. Turbocharger rotor: (a) rotor finite element model; (b) free-free rotor modes at zero rotor speed
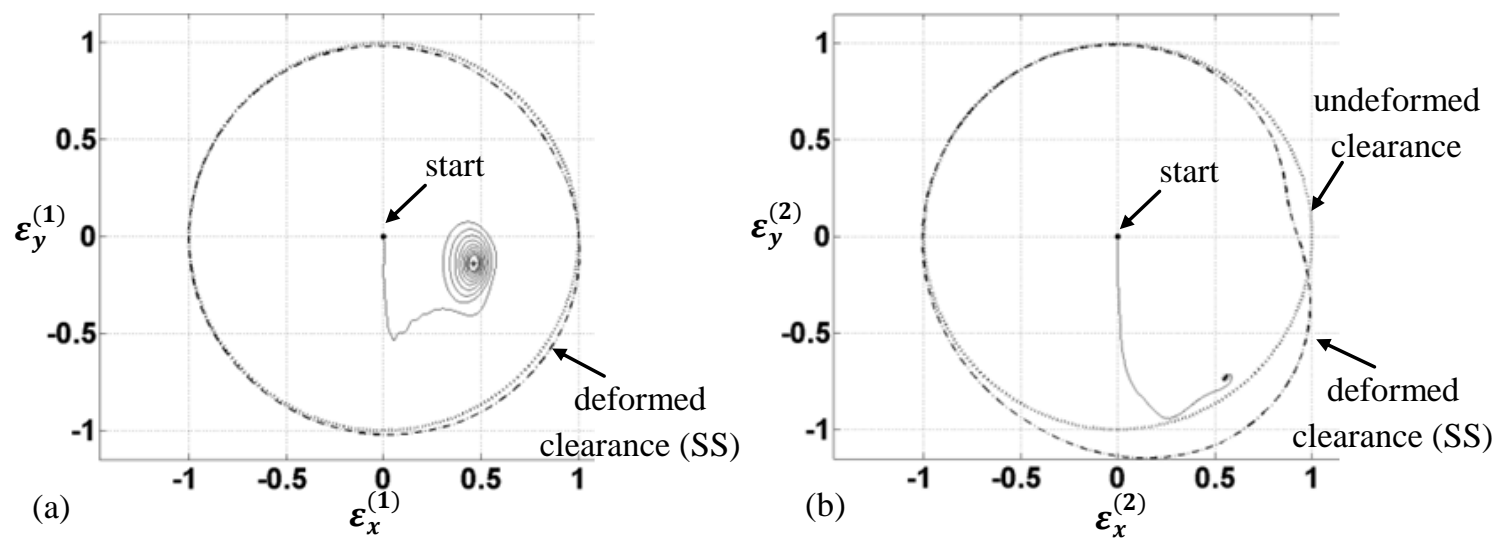

Figure 3. FAB journal trajectories at $5000 \mathrm{rpm}$ from default initial conditions over 20 revs, Test 1 :

(a) FAB1; (b) FAB 2 (SS: steady-state)

Figure 3 shows the simulation of the trajectory (TNDA) of the journal centres $\left(\mathrm{J}_{1}, \mathrm{~J}_{2}\right)$ of the two bearings from default initial conditions (corresponding to centralized journals with zero velocities, air films at atmospheric pressure and undeformed foils) over 20 shaft revolutions at a very low speed $\left(5 \times 10^{3} \mathrm{rpm}\right)$ for Test 1 parameters (Table 1). Both trajectories converge to a 
(stable) static equilibrium point; the equilibrium position of $\mathbf{J}_{2}$ is situated at a lower position in the clearance than that of $\mathrm{J}_{1}$ since $\mathrm{J}_{2}$ supports a considerably larger static load $(4.7 \mathrm{~N} v s 1.4 \mathrm{~N}$ - it is much closer to the centre of gravity G, see Figure 2(b)). Figure 3 also shows the predicted steady-state deformation of the clearance (i.e. the profile of the top foil) of FAB1, FAB2.

The steady-state TNDA solution to equation (15) (which, in the case above (Figure 3), is a constant state vector $\mathbf{S}_{\mathbf{E}}$ ) was used as an initial approximation to the SESA process described in section 2.3 to directly compute the equilibria $\mathbf{S}_{\mathbf{E}}$ and their stability over the operating speed range. The same procedure was performed for other test parameters (Table 1). It is noted that, if the SESA process was progressed backward (rather than forward) from the starting speed of $5 \times 10^{3} \mathrm{rpm}$ to a very low speed, the computed equilibria $\mathbf{s}_{\mathbf{E}}$ approach the static equilibrium condition at null rotor speed (i.e. journals resting at the bottom of a deformed clearance under the rotor weight). If such an equilibrium $\mathbf{s}_{\mathbf{E}}$ were used as the initial condition for the TDNA analysis at $5 \times 10^{3} \mathrm{rpm}$, instead of that marked in Figure
3 , the journal centre and foil deformation would arrive at exactly the same steady-state condition. This is to be expected since, in a dissipative nonlinear system, the choice of the initial conditions of the TDNA normally has no effect on the steadystate condition. The default initial condition used in Figure 3 is very convenient since it corresponds to zero foil deflection and atmospheric pressure (i.e. does not require the prescription of an assumed deformed profile and pressure distribution).

Figures $4(a, b)$ show the real and imaginary parts of the leading eigenvalue $\lambda_{\mathrm{L}}$ over a speed range of $5 \times 10^{3}-200 \times 10^{3} \mathrm{rpm}$ for the SESA of Tests 1-3. The Test 1 stability plot in Figure 4(a) shows that the static equilibrium configuration is stable at $\mathrm{A}$ $\left(5 \times 10^{3} \mathrm{rpm}-\right.$ in agreement with the TNDA of Figure 3$)$ but becomes unstable as the speed is increased slightly to $6 \times 10^{3}$ rpm (point B). Hence, there is a Hopf bifurcation (marking the birth of a limit cycle $[1,18])$ at point $\mathrm{H}\left(\right.$ where $\left.\operatorname{Re}\left\{\lambda_{\mathrm{L}}\right\}=0\right)$.

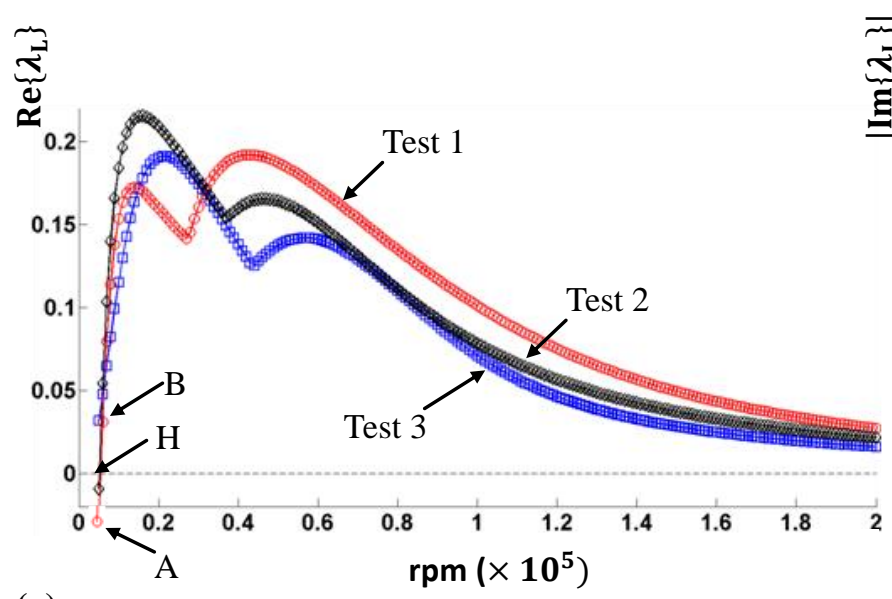

(a)

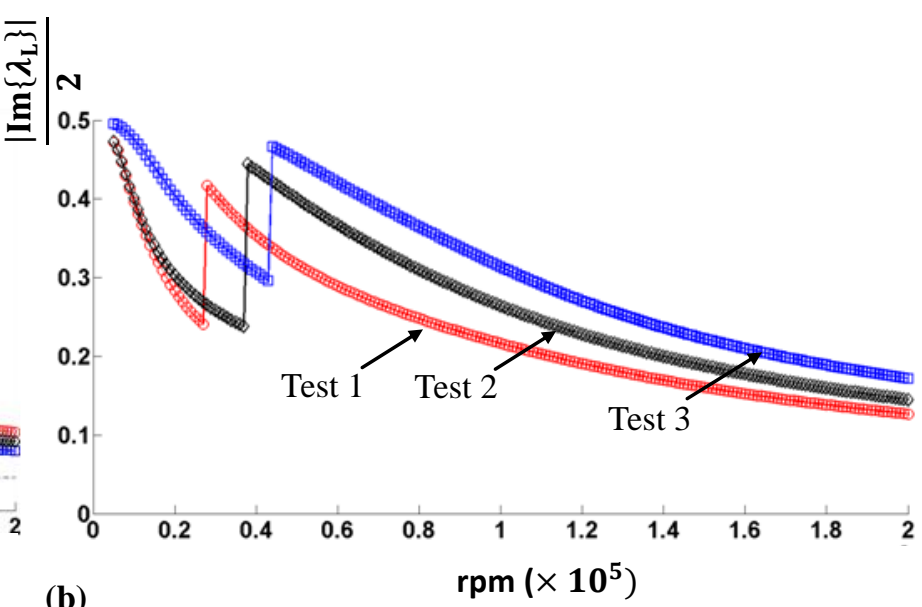

(b)

Figure 4. SESA results for Tests 1-3: (a) perturbation growth factor; (b) ratio of perturbation frequency to rotor speed

The predicted instability of $\left.\mathbf{s}_{\mathbf{E}}\right|_{6 \times 10^{3} \mathrm{rpm}}$ in Test 1 is confirmed by the TNDA results in Figure 5, which show the evolution, over 200 shaft revolutions, of the trajectories of $\mathbf{J}_{1}$ and $\mathbf{J}_{2}$ from slightly perturbed initial conditions $\mathbf{s}(0)=\left.\mathbf{s}_{\mathbf{E}}\right|_{6 \times 10^{3} \mathrm{rpm}}+\Delta \mathbf{S}$ (these are identical to $\left.\mathbf{s}_{\mathbf{E}}\right|_{6 \times 10^{3} \mathrm{rpm}}$ except for the entries corresponding to the q-subvector, which are perturbed by $1 \%$ ); the trajectories are seen to diverge from $\left.\mathbf{S}_{\mathbf{E}}\right|_{6 \times 10^{3} \mathrm{rpm}}$ and eventually settle down into a limit cycle. The limit cycles balloon in size as the speed is increased, as can be seen in Figure 6, which pertains to a speed of $100 \times 10^{3} \mathrm{rpm}$ and shows the evolution to a limit cycle, over 250 shaft revolutions, as a result of a $1 \%$ perturbation in the $\mathbf{q}$-subvector of $\left.\mathbf{S}_{\mathbf{E}}\right|_{100 \times 10^{3} \mathrm{rpm}}$. It is noted that, in both Figures 5 and 6, the plotted deformed clearance profile for each bearing is that corresponding to the instant when its journal is at maximum eccentricity during the limit cycle (e.g. point $\mathrm{E}$ in Fig. 5(a)). In the case of the limit cycle at $100 \times 10^{3} \mathrm{rpm}$ it is seen that the clearance expands to over four times its initial (undeformed) value; however, this still corresponds to a feasible foil deformation since the undeformed clearance $c$ is only $8 \times 10^{-6} \mathrm{~m}$ (see Table 1 ).

The plots of $\left|\operatorname{Im}\left\{\lambda_{\mathrm{L}}\right\}\right| / 2$ in Figure 4(b) show the ratio of the frequency of the dominant perturbation (in the vicinity of the static equilibrium configuration) to the rotational speed, as discussed in section 2.3. Such plots exhibited one or more abrupt shifts in frequency. It is interesting to note that abrupt vibration frequency shifts have also been reported, both theoretically and experimentally, on turbochargers with oil FRBs e.g. [20]. As also noted in [20], an abrupt frequency shift happens whenever one of the $n_{\text {state }}$ eigenvalues supersedes another to become the leading eigenvalue $\lambda_{\mathrm{L}}$ as the speed changes (see definition of $\lambda_{\mathrm{L}}$ in Nomenclature): in fact, the shifts in Figure 4(b) coincide with kinks in Figure 4(a)). 

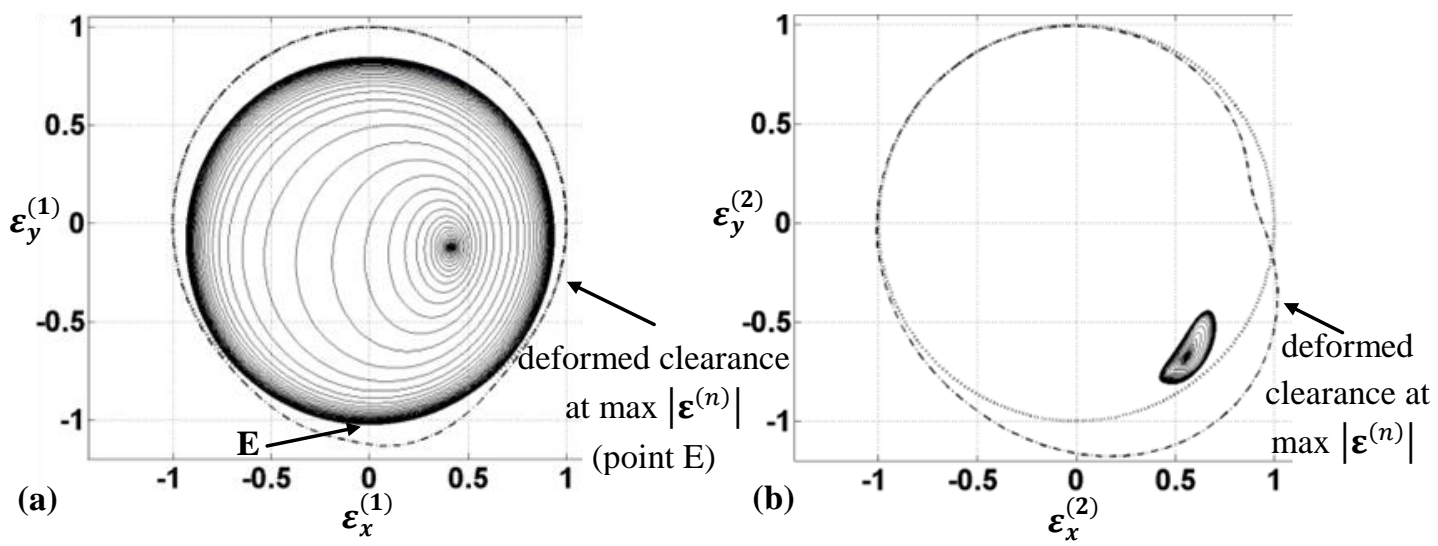

Figure 5. Divergence of $\mathrm{FAB}$ journal trajectories at $6000 \mathrm{rpm}$ from $1 \%$ perturbed static equilibrium over 200 revs,

Test 1: (a) FAB1; (b) FAB 2
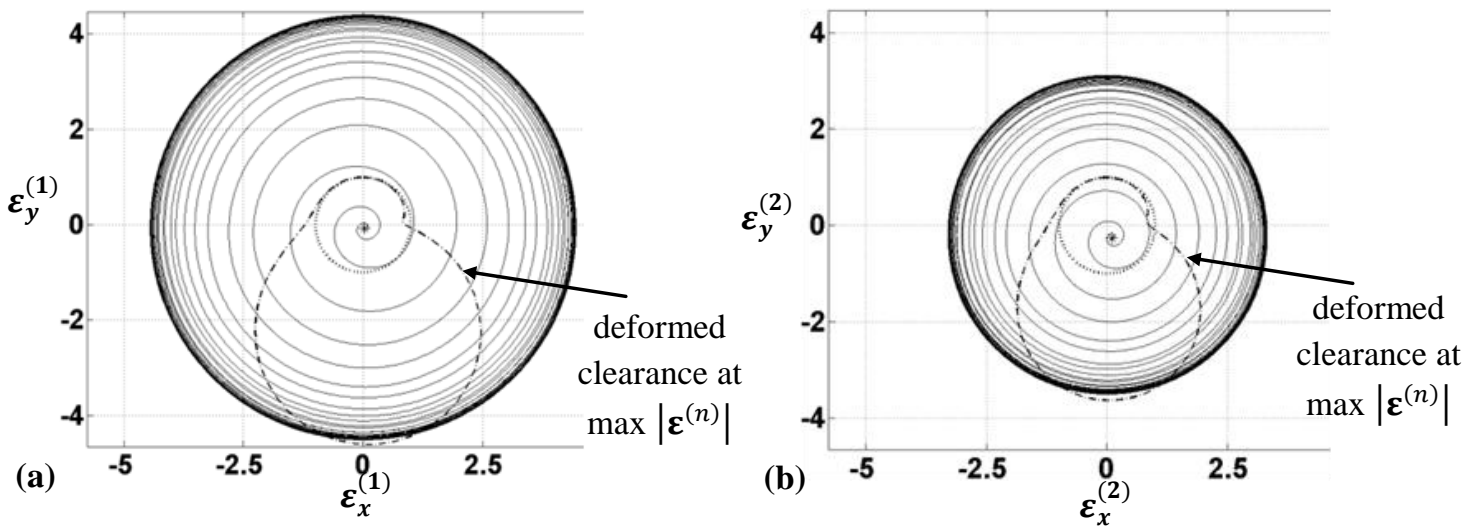

Figure 6. Divergence of FAB journal trajectories at 100,000 rpm from $1 \%$ perturbed static equilibrium over 250 revs, Test 1:(a) FAB1; (b) FAB 2

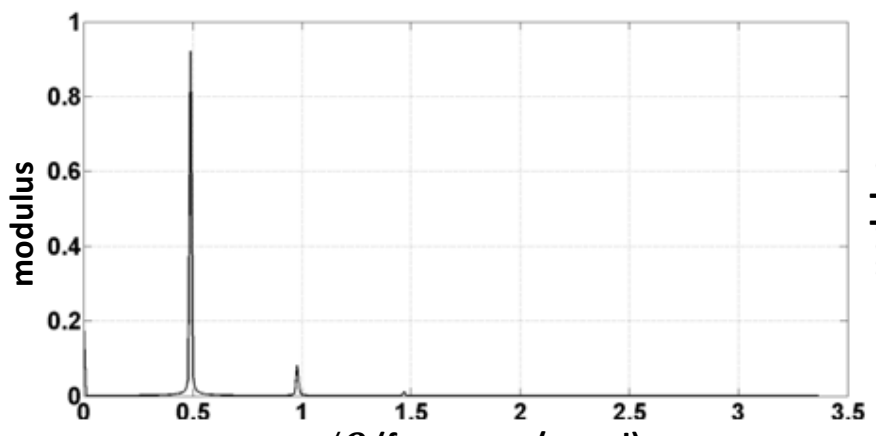

(a)

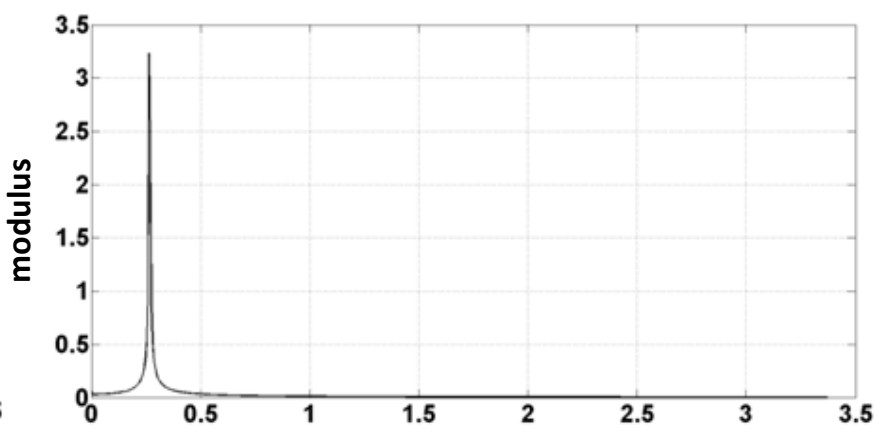

(b)

$\omega / \Omega$ (frequency/speed)

Figure 7. Frequency spectra of the Test 1 limit cycles (FAB 1, $y$ direction): (a) $6000 \mathrm{rpm}$; (b) 100,000 rpm.

Figure 7 shows the frequency spectra of the Test 1 limit cycles (FAB 1, $y$ direction) at $6 \times 10^{3} \mathrm{rpm}, 100 \times 10^{3} \mathrm{rpm}$. It is seen that their fundamental frequency to rotational speed ratios are respectively $0.49,0.26$ (the non-dimensional frequency resolution of the spectrum being 0.005). It is observed that these whirl frequency ratios are quite close to the ratios 0.46 , 0.22 given by the Test 1 curve in Figure 4(b) at the same speeds, despite the fact that (as seen from Figures 5, 6) the limit cycles (for which Figure 7 applies) are considerably removed from the perturbation in the immediate vicinity of the unstable static equilibrium (for which Figure 4(b) applies). It is seen that, at low speed, the instability loosely corresponds to a case of 'half-frequency whirl' (as far as the fundamental frequency to speed ratio is concerned); as the speed increases, the whirl 
frequency appears to approach a limiting value of between a tenth and a fifth of the rotational speed (Figure 4(b)).

The Test 1-3 results in Figure 4(a) show that, increasing the $L / R$ ratio to 2 tends to reduce the degree of instability (the perturbation growth factor) in the second half of the speed range, which is the typical operating range for this turbocharger. Hence, the $L / R$ ratio was maintained at 2 in the subsequent tests. Figure 8(a), which pertains to Tests 3-5 (Table 1), shows the effect of the foil stiffness on the stability plots. Decreasing foil stiffness tends to reduce the growth factor. Figure 8(b) shows the stability plots for the same parameters except for a reduced clearance $c$ (Tests 6-8, Table 1). Comparing Figures $8(\mathrm{~b})$ to $8(\mathrm{a})$, it is seen that, by reducing the clearance from $0.25 c_{0}$ to $0.1 c_{0}$, stability is achieved beyond $60 \times 10^{3} \mathrm{rpm}$ for a foil stiffness of $k_{b 0}$ and beyond around $40 \times 10^{3} \mathrm{rpm}$ for a foil stiffness of $0.5 k_{b 0}$. The stability regime was confirmed by time transient integration at specific speeds. Figures 9(a)(i),(b)(i) shows the evolution, over 50 shaft revolutions, of the trajectories of $J_{1}$ and $J_{2}$, as a result of a $20 \%$ perturbation in the $\mathbf{q}$-subvector of the static equilibrium solution at $100 \times 10^{3} \mathrm{rpm},\left.\mathbf{s}_{\mathbf{E}}\right|_{100 \times 10^{3} \mathrm{rpm}}$ (Test 7 parameters). Figures 9(a)(ii),(b)(ii) show the trajectories over the last 50 of a further 150 revolutions: it is clear that, despite the sizeable initial perturbation, the journal centres settle back to their static equilibrium positions. Figure 9(b)(ii) also shows that, despite the larger static offset of $\mathbf{J}_{2}$ (from the bearing centre), $\mathbf{J}_{2}$ is still approximately centralized within the deformed clearance boundary. It is also noted that the SESA results showed that the static condition depicted Figures 9(a)(ii),(b)(ii) is virtually invariant over the entire speed range.

As a final observation, given that the results of this case study indicated that reduction in undeformed clearance promoted stability, any centrifugal growth of the journal should be beneficial in this respect.

\section{CONCLUSIONS}

The research in this paper has presented a generic technique for the TNDA and SESA of a turbomachine running on FABs. The FD state equations of the two air films were preserved and solved simultaneously with the state equations of the foil structures and the state equations of the modal model of the turbomachine. An efficient analysis was possible through the extraction of the state Jacobian matrix using symbolic computing. The method was applied to an actual turbocharger rotor currently running on two oil FRBs that was slightly modified to run on two FABs instead. The results of the SESA were shown to be perfectly consistent with those from the TNDA. For certain FAB parameters, limit cycles were observed over a wide speed range, and the ratio of their fundamental frequency to the rotational speed reduced from around 0.5 to a lower order as the speed was increased, subject to abrupt frequency shifts revealed by the SESA - similar behaviour has also been observed in turbochargers with oil FRBs. The case study showed that stability of the static equilibrium configuration was promoted by increasing the FAB length-to-radius ratio, increasing the foil structure compliance and reducing the undeformed radial clearance. With the right parameters, stability was achievable over a wide operating range, in contrast to the current installation (FRBs). The foil deformation ensured that the heavily loaded journal was still centralised in the altered clearance. Future research will aim to extend this analysis to more complex foil structure models involving Coulomb friction and/or interaction between bumps.

\section{ACKNOWLEDGMENTS}

The authors acknowledge the support of the Engineering and Physical Sciences Research Council (EPSRC) of the United Kingdom for its support through grant EP/I029184/1.

\section{REFERENCES}

[1] Pham, H.M., Bonello, P., 2013, "Efficient Techniques for the Computation of the Nonlinear Dynamics of a Foil-Air Bearing Rotor System". Proceedings of the ASME Turbo Expo 2013, San Antonio Convention Center, San Antonio, Texas, USA, June 2013, Paper no. GT2013-94389.

[2] Bonello, P., Pham, M.H., "The efficient computation of the nonlinear dynamic response of a foil-air bearing rotor system", under review by J. Sound and Vibration.

[3] Le Lez, S., Arghir, M., Frene, J., 2009, "Nonlinear Numerical Prediction of Gas Foil Bearing Stability and Unbalanced Response," ASME J. Engineering for Gas Turbine and Power, 131, 012503.

[4] Wang, C-C., Chen, C-K., 2001, "Bifurcation of Self-Acting Gas Journal Bearings,” ASME J. Tribology, 123, pp. 755-767.

[5] Zhang, J., Kang, W., Liu, Y., 2009, "Numerical Method and Bifurcation Analysis of Jeffcott Rotor System Supported in Gas Journal Bearing," ASME J. Computational and Nonlinear Dynamics, 4, 011007.

[6] Kim, D., 2007, "Parametric Studies on Static and Dynamic Performance of Air Foil Bearings with Different Top Foil Geometries and Bump Stiffness Distributions," ASME J. Tribology, 129, pp. 354-364.

[7] Song, J., Kim, D., 2007, "Foil Gas Bearing with Compression Springs: Analyses and Experiments," ASME J. Tribology, 129, pp. 628-639.

[8] Lee, D-H., Kim, Y-C., Kim, K-W., 2009, “The Dynamic Performance Analysis of Foil Bearings Considering Coulomb Friction: Rotating Unbalance Response”, Tribology Trans., 52, pp.146-156.

[9] Marco Tulio C. Faria, Luis San Andres, 2000, "On the Numerical Modeling of High-Speed Hydrodynamic Gas Bearings,” ASME J. Tribology, 122, pp. 124-130.

[10] Shampine, L.F., Reichelt, M.W., 1997, "The Matlab ODE suite". SIAM J. Sci. Comput. 18(1), pp.1-22.

[11] Kim, D., Lee, A.S., Choi, B.S., 2013, "Evaluation of Foil Bearing Performance and Nonlinear Rotordynamics of $120 \mathrm{~kW}$ Oil-Free Gas Turbine Generator". Proceedings of the ASME Turbo Expo 2013, San Antonio Convention Center, San Antonio, Texas, USA, June 2013, Paper no. GT2013-95800. 
[12] Lee, D, Kim, D., 2010, "Five Degrees of Freedom nonlinear Rotor Dynamics Model of a Rigid Rotor Supported by Multiple Airfoil Bearings". Proceedings of the 8th IFToMM International Conference on Rotor Dynamics, KIST, Seoul, Korea, 12-15 September 2010, pp. 819-826.

[13] Bonello, P., 2009, "Transient Modal Analysis of the Nonlinear Dynamics of a Turbocharger on Floating Ring Bearings," Proceedings of the Institution of Mechanical Engineers - Part J: Journal of Engineering Tribology, 223, pp 79-93.

[14] Peng, Z-C., Khonsari, M. M., 2004, "Hydrodynamic Analysis of Compliant Foil Bearings with Compressible Air Flow," ASME J. Tribology, 126, pp. 542-546.

[15] Ewins, D.J., 2000, "Modal Testing: Theory, Practice, and Application", 2nd ed. Research Studies Press, Baldock.
[16] Groves, K.H., Bonello, P., 2010, "Improved Identification of Squeeze-Film Damper Models for Aeroengine Vibration Analysis, Tribology International, 43 (9), pp. 1639-1649.

[17] Dahlquist, G., 1974, "Numerical methods", Prentice-Hall, Englewood Cliffs N.J.

[18] Seydel, R, 1994, "Practical Bifurcation and Stability Analysis: From Equilibrium to Chaos”. Springer-Verlag, New York.

[19] Kirk, R.G., Alsaeed, A.A., Gunter, E.J., 2007, "Stability Analysis of a High-Speed Automotive Turbocharger", Tribology Transactions, Tribology Trans., 50:3, pp. 427-434.

[20] Holmes, R, Brennan, M.J., Gottrand, B., 2004, "Vibration of an Automotive Turbocharger - a Case Study". Proceedings of the 8th International Conference on Vibrations in Rotating Machinery, University of Wales, Swansea, UK, 7-9 September 2004, IMechE Conference Transactions, 2004-2, pp. 445-455.
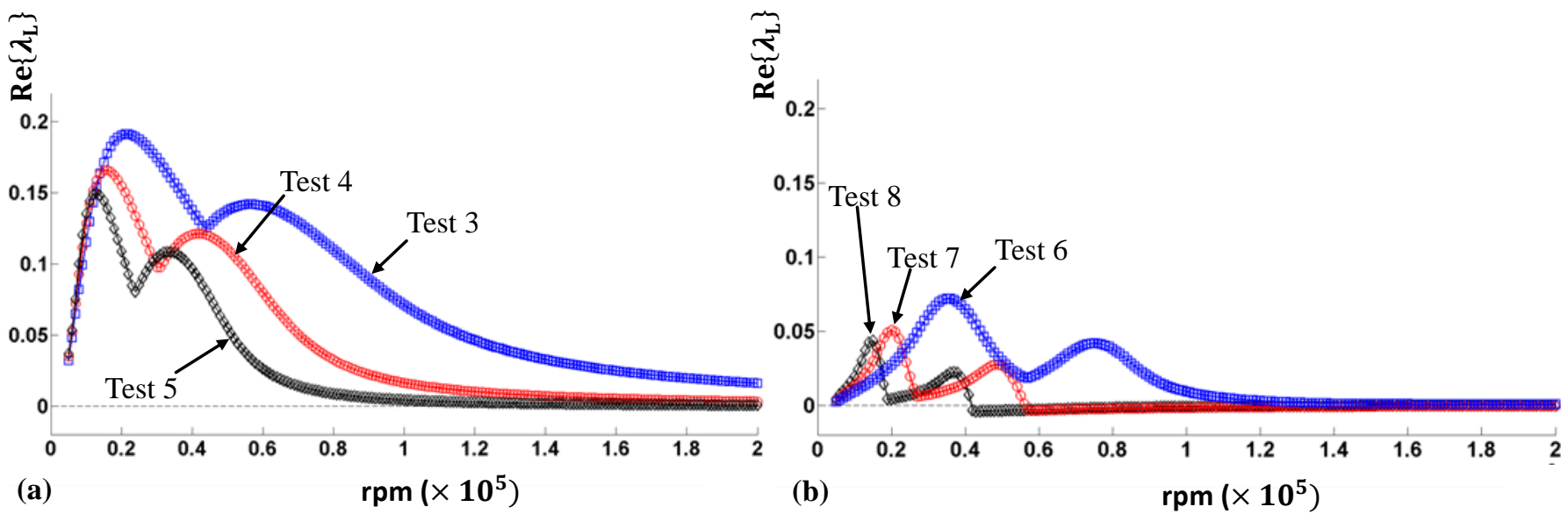

Figure 8. SESA results (perturbation growth factor): (a) tests 3-5; (b) tests 6-8

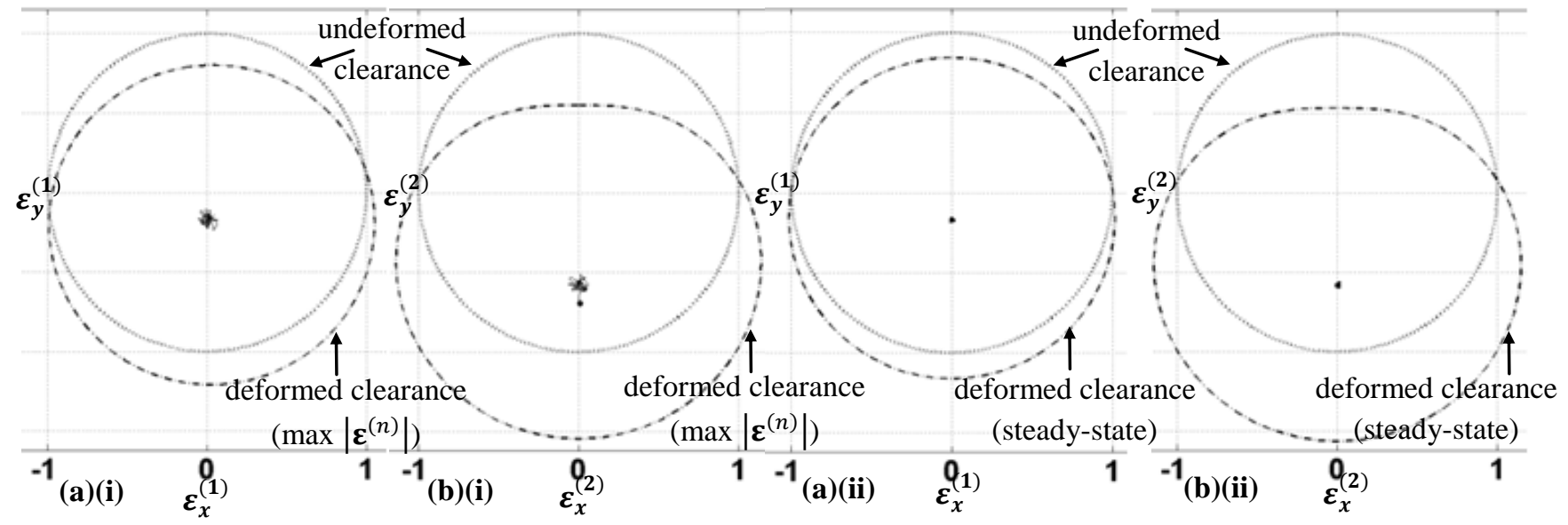

Figure 9. FAB journal trajectories at $100,000 \mathrm{rpm}$ from $20 \%$ perturbed static equilibrium, Test 7 :

(a)(i), (b)(i) FAB1, FAB2, first 50 revs; (a)(ii), (b)(ii) FAB1, FAB2, last 50 revs out of further 150 revs 